\title{
Serial assessment of circumferential regional left ventricular function following complete coronary occlusion
}

\begin{abstract}
The effect of abrupt coronary artery occlusion on regional left ventricular (LV) function is well known, but serial changes in circumferential regional function over the first few hours have not been extensively investlgated. Circumflex coronary artery occlusion was produced in nine closed-chest, conscious dogs and changes in LV circumferential function were assessed using two-dimensional echocardiography (2DE) performed in the short-axis projection at the mid-papillary muscle level. End-diastolic and end-systolic frames were manually digitized and regional area ejection fractions at 22.5-degree intervals were calculated using a fixed diastolic center of mass. Endocardial motion abnormality was measured from a circumferential regional ejection fraction map. The extent of wall motion abnormality was measured as that exceeding $95 \%$ confidence limits of normal controls; the degree of dys8ynergy was measured as the planimetered area of the extent of wall motion abnormality. Following circumflex coronary artery occlusion, a wall motion abnormality was well defined with a minute of occlusion and its circumferential extent measured $146 \pm 16$ degrees with $11 \pm 2 \mathrm{~cm}^{2}$ absolute degree of dyssynergy. These parameters did not change over the course of the coronary artery occlusion. We conclude that circumferential regional abnormalities produced by coronary occlusions are well defined early and do not change over the first 3 hours of acute ischemia and infarction. (AM HeART J 112:447, 1986.)
\end{abstract}

Andrew J. Buda, M.D., and Rainer J. Zotz, M.D. Ann Arbor, Mich.

Two-dimensional echocardiography (2DE) has recently been used to spatially localize and quantify regional left ventricular functional abnormalities related to acute ischemia and infarction. Although several studies have examined the ability of $2 \mathrm{DE}$ functional abnormalities to predict infarct size, ${ }^{1-6}$ relatively few studies have studied serial changes in the two-dimensional regional abnormality over the first several hours of ischemia and infarction. Various quantitative models have been introduced, most of which use radial measurements toward an assumed centroid. As few as 8 to as many as 180 radii have been used in the quantitative models., Whereas eight radii limit spatial sampling and result in overlap between normal and abnormal function-

From the Cardiology Division, Department of Internal Medicine, University of Michigan Medical School.

This work was supported in part by a Grant-in-Aid from the American Heart Assuciation of Michigan, and by Grant HL 29716 from the National Heart. Lung, and Blood Institute, National Institutes of Health, Bethesda $\mathrm{Md}$

Received for publication June 13, 1985; revision received Dec. 16, 1985 accepted Jan. 20, 1986

Reprint requests: Andrew J. Buda, M.D., Cardiology Division, University of Michigan Medical Center, 1405 E. Ann St., Ann Arbor, MI 48109. ing regions, 180 radii make the presence of noise more obvious than the use of fewer radii and require sophisticated data processing capabilities in the analysis of the functional profiles. Most laboratories $^{5,6,9-11}$ have compromised between 12 and 24 radii as a manageable number of sectors to analyze that will provide adequate spatial localization.

The purpose of this report is twofold. First, we describe serial regional left ventricular function abnormalities in a conscious canine model over the first 3 hours of coronary occlusion. Second, we introduce a simple method to analyze the circumferential left ventricular functional data generated by 2DE analysis.

\section{METHODS}

Animal model. Nine conditioned dogs were studied. Each dog was anesthetized with morphine, $3 \mathrm{mg} / \mathrm{kg}$ intravenously, and sodium pentobarbital, $30 \mathrm{mg} / \mathrm{kg}$ intravenously. Artificial respiration was performed with a Harvard respirator. A left thoracotomy was done under sterile conditions and the left circumflex coronary arery was dissected free from surrounding tissue. A hydraulic occluder was placed on the proximal left circumflex coronary artery. An indwelling silicone rubber catheter was placed in the ascending aorta for pressure measure- 


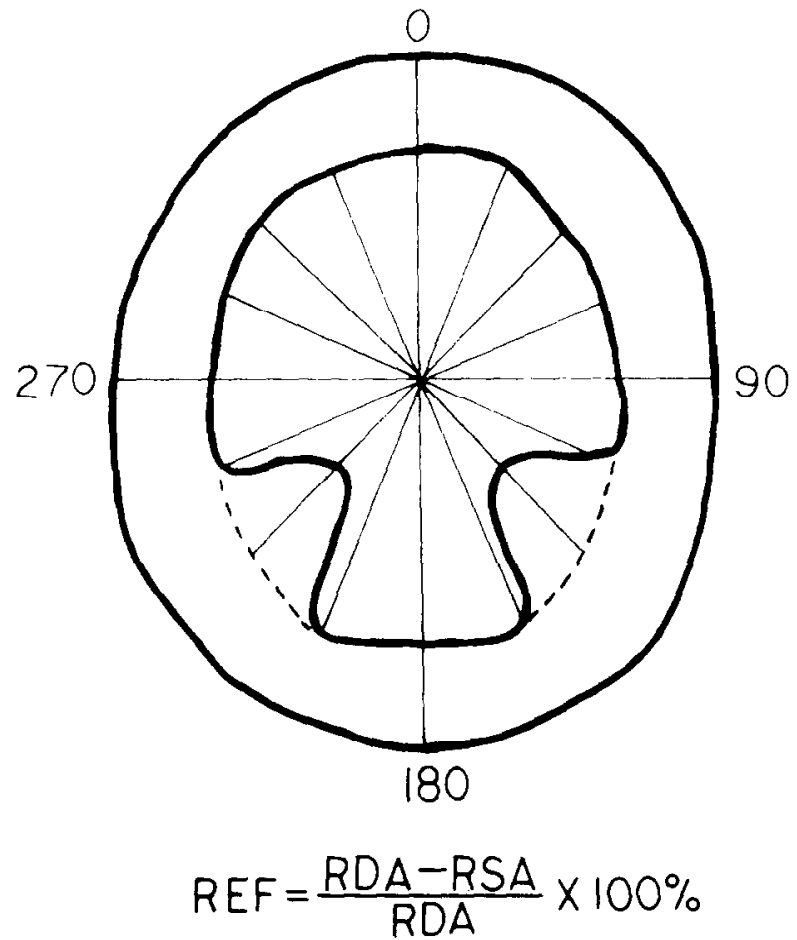

Fig. 1. A schematic of the short-axis two-dimensional echocardiogram (2DE) at the level of the midpapillary muscle illustrating the radial contraction model for determination of regional ejection fraction $(R E F)$. A fixed diastolic centroid was used and the endocardial circumference was divided into 16 sectors of 22.5 degrees each. For correction of rotation, the midpoint of the posterior papillary muscle was displayed and fixed at 135 degrees. $R D A=$ regional diastolic area; $R S A=$ regional systolic area.

ment and in the superior vena cava for injection of drugs. The catheters were brought out of the chest through a subcutaneous tunnel to the back and were secured to the skin between the scapulae. The chest cavity was closed and the pneumothorax was evacuated. Catheters were flushed daily with $1,000 \mathrm{U} / \mathrm{ml}$ of heparin. Antibiotics were administered intramuscularly prior to and following surgery. The animals were allowed to recover from surgery for 14 days.

2DE acquisition. 2DE was performed with a commercially available phased-array sector scanner and a 2.25 $\mathrm{MHz}$ transducer, with the animal in the right lateral decubitus position on a table with a cut-out that allowed transducer placement on the right lateral precordium. The best acoustic window was determined and was marked externally with ink to insure reproducible positioning of the transducer. In some animals, the transducer was clamped in place for the duration of the study. In those animals in which a clamp was not used, there was an attempt to reproduce the same angulation of transducer position using the $2 \mathrm{DE}$ image as a guide. Care was taken to visualize the same region of the papillary muscles, using the shape of the papillary muscles as a specific anatomic landmark. 2DE was performed in the short-axis projection at the level of the midpapillary muscle and was recorded on a $1 / 2$-inch video cassette recorder in real time for later review and analysis.

Protocol. At 14 days following surgery, each conscious animal was studied. After baseline 2DE studies, the left circumflex coronary artery was occluded. Coronary occlusion was associated with typical ECG changes and regional abnormalities on 2DE. Serial 2DE studies were recorded at 5 minutes, 1 hour, and 3 hours of coronary occlusion.

2DE analysis. With a commercially available minicomputer based, video digitizing system (Diasonics CRC, Milpitas, Calif.), end-diastolic and end-systolic frames were selected for analysis. The end-diastolic frame selected was the one demonstrating the largest endocardial area and generally corresponded to the onset of the $Q$ wave in lead II of the ECG. The end-systolic frame selected was the one demonstrating the smallest endocardial area and generally corresponded to the end of the $T$ wave. An experienced operator carefully traced the endocardial border directly from the video display with a digitizing tablet. The papillary muscles were excluded from the endocardial outline but the midpoint of the posterior papillary muscle was identified for rotation correction. Endocardial motion abnormality was calculated by means of a radial contraction model. In this model, a fixed external reference system with rotation correction was employed. The reference system superimposed the external calibration scale for both end-diastolic and endsystolic frames. The centroid was identified on the enddiastolic frame by means of an algorithm that separately sums the $\mathrm{X}$ and $\mathrm{Y}$ screen addresses of every point enclosed by the outline and then divides each sum by the number of points considered. This centroid, which represents the averaged location within the outline, was fixed for the end-systolic frame analysis. Thus, there was no correction for systolic translation, which in our experience tends to minimize wall motion abnormality. However, there was correction for rotation by using the midpoint of the posterior papillary muscle which was fixed at 135 degrees. The error in identifying this midpoint position is \pm 5 degrees. With this coordinate system, the endocardial outline was divided into 16 sectors by creating radii from the centroid to the endocardial border at 22.5 degrees over the full 360 degrees. Regional ejection fraction was calculated for each individual sector as: end-diastolic area minus end-systolic area/end diastolic area $\times 100 \%$ (Fig. 1). By the use of these regional ejection fractions, a functional map was derived for each normal and occlusion condition. The $95 \%$ confidence limits for each of the regional ejection fractions was determined from the baseline studies and the lower $95 \%$ confidence limit was used to define the lowest limit of normal. With the lower confidence limits, abnormal regional function for each occlusion condition was expressed as the circumferential extent (in degrees) and degree of dysfunction (centimeters squared) measured directly from each animal occlusion function map. The extent of dysfunction was measured at the curve intercepts between the occlusion and normal 

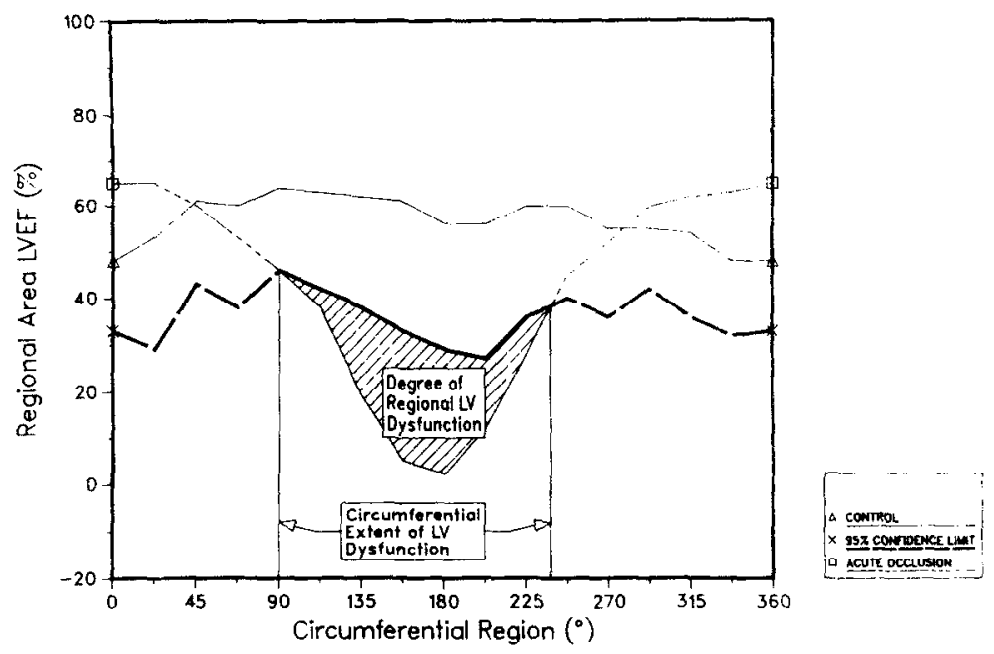

Fig. 2. A functional map displaying regional area left ventricular ejection fraction ( $L V E F)$ for each of the 16 sectors over the 360 degrees. Control $(\Delta)$ and occlusion $(\square)$ profiles are illustrated from one animal study. The lower $95 \%$ confidence limit (X) is indicated by the bold and broken line. Abnormal regional function is measured as the degree of dysfunction (planimetered area of the map that is abnormal) and the circumferential extent of dysfunction (measured at the curve intercepts between the occlusion and normal maps).
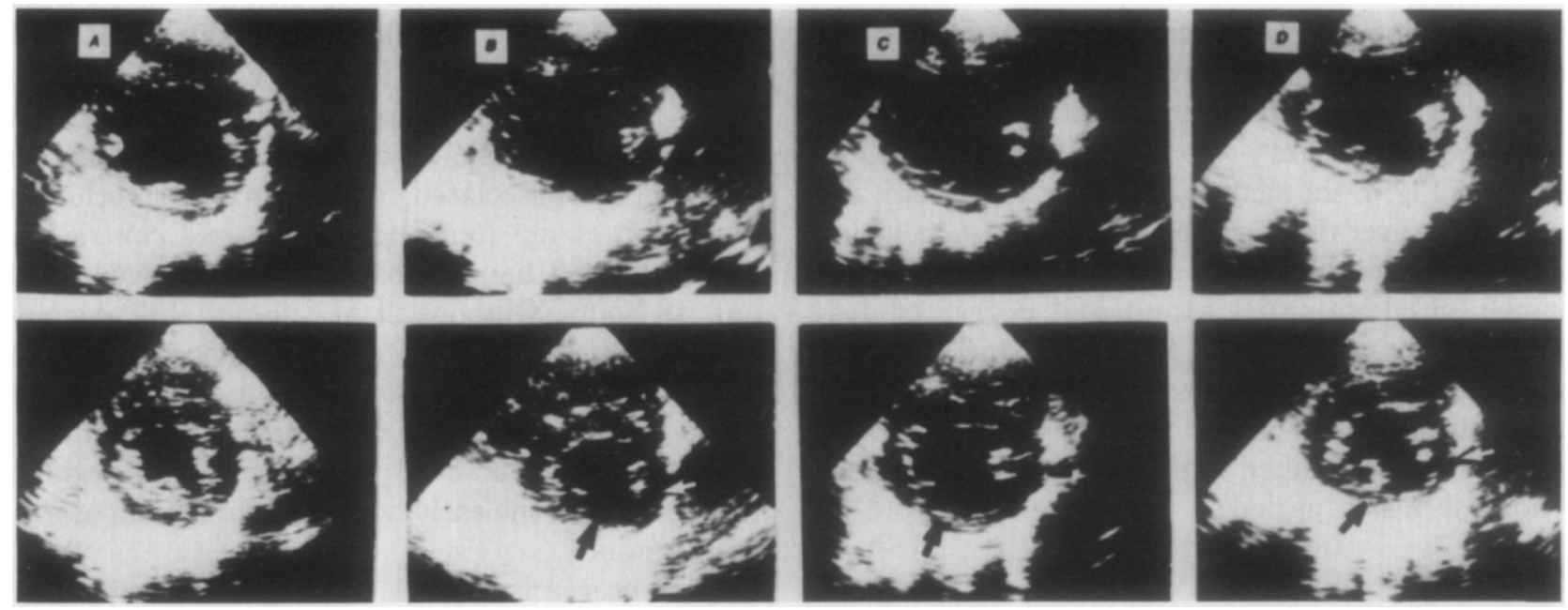

Fig. 3. An individual experimental study at baseline (A) and then at 5 minutes' occlusion (B), at 30 minutes' ocelusion $(C)$, and at 180 minutes' occlusion $(D)$. The end-diastolic frame is above and the end-systolic frame is below for each time point. The arrows in the end-systolic frames during occlusion mark the extent of regional dysfunction.

maps; the degree of dysfunction was measured as the planimetered area of the map that was abnormal (Fig. 2).

Statistical analysis. All values are expressed as mean \pm standard error of the mean. Statistical comparison of hemodynamics, regional ejection fraction, extent and degree of left ventricular dysfunction at serial time points was made using a one-way analysis of variance (ANOVA). The probability ( $p$ ) was considered to be statistically significant when $<0.05$.

\section{RESULTS}

Following coronary artery occlusion, there were no significant changes in heart rate and mean arterial pressure. However, each animal developed within seconds of occlusion an obvious wall motion abnormality in the region of the posterior papillary muscle, corresponding to the perfusion bed of the left circumflex coronary artery (Fig. 3). By 5 minutes, the endocardial wall motion abnormality was well defined and the circumferential extent of 


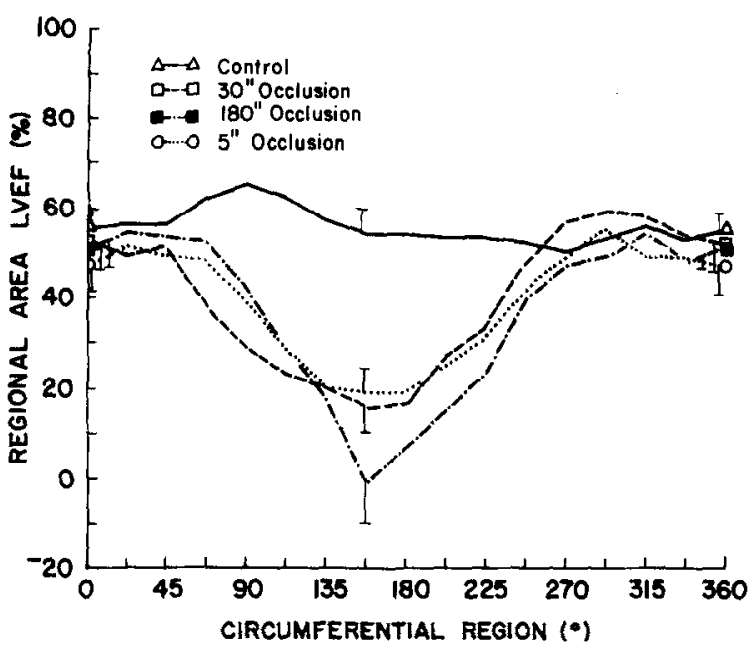

Fig. 4. Regional area left ventricular ejection fraction ( $L V E F)$ maps at control, at 5 minutes' occlusion, at 30 minutes' occlusion, and at 180 minutes' occlusion. Note that the shape of the occlusion maps are similar without significant change over the duration of the 3-hour coronary occlusion.

this abnormality measured $146 \pm 16$ degrees, or approximately $41 \%$ of the circumference of the left ventricle. The serial changes and left ventricular regional function are presented in Table 1 . As illustrated in Fig. 4, the shape of the functional maps did not change over the duration of the 3-hour occlusion period. The derived parameters from these maps, namely circumferential extent and degree of dysfunction, are summarized in Figs. 5 and 6. There were no significant changes in these functional parameters, which were well demarcated at 5 minutes and remained stable over the subsequent 3-hour occlusion period.

\section{DISCUSSION}

Functional abnormality following coronary occlusion. Since the classic observations by Tenant and Wiggers $^{12}$ a half century ago, it has been well known that regional contractile function becomes abnormal within seconds of coronary occlusion. More recent sonomicrometry studies ${ }^{13,14}$ have demonstrated that the regional abnormality sampled by implanted crystals remains abnormal for the duration of the coronary occlusion, with no significant changes over the initial hours of occlusion. However, it wasn't until the development of $2 \mathrm{DE}$ that the two-dimensional spatial characteristics of the regional ischemic abnormality could be defined in greater detail.

Our results indicate that the circumferential extent and degree of dysfunction of the left ventricle in two dimensions are well established within 5
Table I. Serial changes in LV regional function

\begin{tabular}{lrrr}
\hline $\begin{array}{c}\text { Time after occlusion } \\
(\mathrm{min})\end{array}$ & 5 & 30 & 180 \\
\hline $\begin{array}{l}\text { Normal REF (\%) } \\
\text { Ischemic REF (\%) }\end{array}$ & $50 \pm 5$ & $51 \pm 6$ & $53 \pm 4$ \\
$\begin{array}{l}\text { Circumferential extent } \\
(\text { degrees })\end{array}$ & $19 \pm 5^{*}$ & $16 \pm 6^{*}$ & $-1 \pm \pm 9^{*}$ \\
$\begin{array}{l}\text { Degree of dyskinesis } \\
\left(\mathrm{cm}^{2}\right)\end{array}$ & $11 \pm 2$ & $151 \pm 21$ & $158 \pm 14$ \\
& & & $14 \pm 2$ \\
$\begin{array}{l}\text { REF }=\text { regional ejection fraction. } \\
{ }^{*} p<0.02 \text {, ischemic vs normal. }\end{array}$ & & & \\
\end{tabular}

minutes of coronary occlusion and do not change significantly over a period of 3 hours. Previous $2 D E$ studies have largely concentrated on attempting to size myocardial infarction by means of the functional abnormalities measured by echocardiography. Most of these studies have found that the actual infarct size is overestimated by the functional abnormality, which appears to correspond better to the ischemic risk area of the myocardium. ${ }^{2-5}$

Serial changes in LV dysfunction. Although a number of studies have examined the ability of the $2 \mathrm{DE}$ function abnormality to size myocardial infarction, relatively few studies have examined serial changes in the two-dimensional characteristics of regional dysfunction associated with coronary occlusion. Nieminen et al. ${ }^{4}$ found that abnormal contracting segments at 2 hours subsequently improved at 24 and 48 hours. Gibbons et al. ${ }^{15}$ found that regional abnormalities following acute coronary occlusion and myocardial infarction often normalized at 6 weeks. However, neither of these studies examined the temporal course of two-dimensional regional dysfunction in the early hours of evolving myocardial infarction.

Our observations were limited to the early time course following infarction and demonstrated that the functional two-dimensional abnormality is well defined by 5 minutes. Since myocardial necrosis does not occur until approximately 20 minutes following acute coronary occlusion, this functional abnormality is entirely related to the severe ischemia resulting from coronary occlusion. Myocardial infarction is known to occur in a wave front phenomenon, occurring after 20 minutes of occlusion and progressing from endocardium to epicardium over the subsequent duration of the occlusion. ${ }^{16}$ Since regional endocardial motion did not change substantially over this time, it is unlikely that cell necrosis independently produces any further change in systolic function in addition to that already induced by ischemia. 


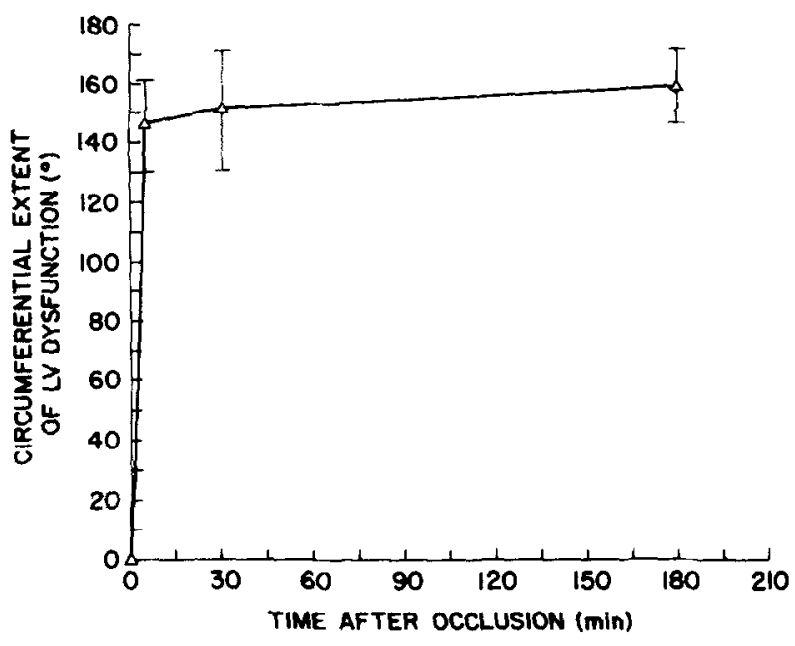

Fig. 5. The circumferential extent of LV dysfunction measured from the regional LVEF maps is illustrated for the serial studies during coronary occlusion. There was no significant change over the duration of the occlusion.

The methodology that was used for regional analysis is a modification of that used by other investigators. There remains uncertainty regarding the appropriate centroid to be used for radial contraction analysis. Our method uses a fixed diastolic centroid, which probably accounts for the fact that the regional ejection fractions that occurred following occlusion remained positive despite severe transmural ischemia. However, since we were more interested in relative changes in $\mathrm{LV}$ function rather than absolute values, different quantitative schemes would likely not influence our final results and conclusions. The use of wall thickening measures have made the centroid less critical in the quantitative analysis, but accurate epicardial definition is sometimes difficult. Previous studies by Pandian and Kerber ${ }^{17}$ correlating 2DE functional abnormalities to sonomicrometry values clearly indicate that 2DE accurately depicts regional dysfunction. Furthermore, Pandian et al. ${ }^{18}$ have demonstrated that both systolic wall thickening and endocardial wall motion are equally as sensitive in assessing regional ischemic changes. The primary difference between these two methods appears to be their respective ability to size the ischemic territory. We have recently found that our method of endocardial wall motion abnormality overestimates the ischemic myocardium at risk, which corresponds better to the extent of the wall thickening abnormality. ${ }^{19}$

In conclusion, our data indicate that left ventricular regional abnormalities in two dimensions are well defined within 5 minutes of coronary occlusion and do not change over the subsequent 3 hours in a

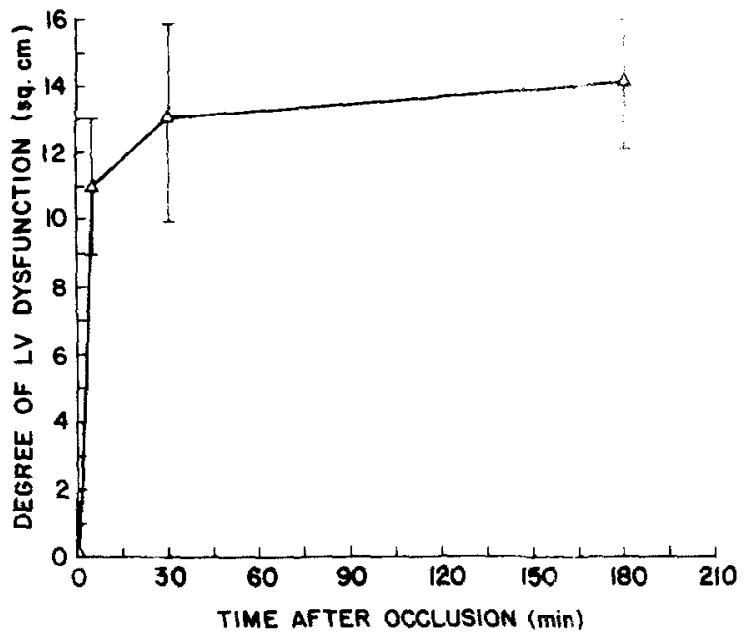

Fig. 6. The degree of LV dysfunction measured from the regional $\mathrm{LVEF}$ maps is illustrated for the serial studies during coronary occlusion. There was no significant change over the duration of the occlusion

conscious animal model. Since $2 \mathrm{DE}$ is readily applicable to clinical situations, our observations have direct relevance to the assessment of two-dimensional regional abnormalities in man during acute myocardial infarction.

We appreciate the assistance of Mary Sue LeMire in perform. ing these experiments. The secretarial assistance of Lisa Hackbarth is gratefully acknowledged.

\section{ADDENDUM}

Since submitting our manuscript, Gillam et al." recently reported similar results in 11 closed-chest dogs. They found that the circumferential extent and magnitude of abnormal wall motion present at 10 minutes after occlusion did not change significantly up to 6 hours later.

\section{REFERENCES}

1. Meltzer RS, Woythaler JN, Buda At, Griffith JC, Harrison WD, Martin RP, Harison DC, Popp RL. Two-dimensional echocardiographic quantification of infarct size alteration by pharmacologic agents. Am J Cardiol 44:257, 1979.

2. Wyatt HL, Meerbaum S, Heng MK, Rit J, Gueret P, Corday E: Experimental evaluation of the extent of myocardial dysenergy and infarct size by two-dimenstional echocardiography. Circulation 63:607, 1981.

3. Lieberman AN, Weiss JL, Jugdutt BI, Becker LC, Bulkley BH, Garrison JC, Hutchins GM, Kallman CA, Weisfeldt ML: Two-dimensional echocardiography and infarct size: Rela tionship of regional wall motion and thickening to the extent of myocaridal infarction in the dog. Circulation 63:739, 1981.

4. Nieminen M, Parisi A, O'Boyle JE, Folland ED, Khuri S, Kloner RA: Serial evaluation of myocardial thickening and thinning in acute experimental infarction: Identification and quantification using two-dimensional echocardiography. Cir culation 66:174, 1981. 
5. Pandian N, Koyanagi S, Skorton D, Collins C, Marcus M Kerber R: Relations between two-dimensional echocardiographic wall thickening abnormalities, myocardial infarct size and coronary risk area in normal and hypertrophied myocardium in dogs. Am J Cardiol 52:1318, 1983.

6. Pandian N, Koyanagi S, Skorton D, Collins S, Marcus M, Kerber R: Serial quantification of myocardial dyskinesis in acute myocardial infarction by two-dimensional echocardiography (abstr). J Am Coll Cardiol 1:619, 1983.

7. Moynihan P, Parisi A, Feldman C: Quantitative detection of regional left ventricular contraction abnormalities by two dimensional echocardiography. I. Analysis of methods. Circulation 63:752, 1981 .

8. Henschke CI, Risser TA, Sandor T, Hanlon WB, Neumann A, Wynne J: Quantitative computer-assisted analysis of left ventricular wall thickening and motion by 2 -dimensional echocardiography in acute myocardial infarction. Am J Cardiol 52:960, 1983.

9. Buda AJ, Delp EJ, Meyer CR, Jenkins JM, Smith DN, Bookstein FL, Pitt B: Automatic computer processing of digital two-dimensional echocardiograms. Am $J$ Cardiol 52:384, 1983.

10. Schnittger I, Fitzgerald PJ, Gordon EP, Alderman EL, Popp RL: Computerized quantitative analysis of left ventricular
Sasayama S: Regional myocardial function and dimensions early and late after myocardial infarction in the unanesthetized dog. Circ Res 40:158, 1977.

14. Sasayama S, Gallagher KP, Kemper WS, Franklin D, Ross J Jr: Regional left ventricular wall thickness early and late after coronary occlusion in the conscious dog. Am J Physiol 240:H293, 1981.

15. Gibbons EF, Hogan RD, Franklin TD, Nolting M, Weyman $\mathrm{AE}$ : The natural history of regional dysfunction in a canine preparation of chronic infarction. Circulation 71:394, 1985.

16. Reimer KA, Lowe JE, Rasmussen MM, Jennings RB: The wave front phenomenon of ischemia cell death. I. Myocardial infarct size vs. duration of coronary occlusion in dogs. Circulation 56:786, 1977.

17. Pandian NG, Kerber RE: Two-dimensional echocardiography in experimental coronary stenosis. I. Sensitivity and specificity in detecting transient myocardial dyskinesis: Comparison with sonomicrometers. Circulation 66:597, 1982.

18. Pandian NG, Skorton DJ, Collins SM, Koyanagi S, Kieo R, Marcus ML, Kerber RE: Myocardial infarct size threshold for two-dimensional echocardiographic detection: Sensitivity of systolic wall thickening and endocardial motion abnormalities in small versus large infarcts. Am J Cardiol 55:551, 1985 .

11. Gillam LD, Hogan RD, Foale RA, Franklin TD, Newell JB, Guyer DE, Weyman AE: A comparison of quantitative echocardiographic methods for delineating infarct-induced abnormal wall motion. Circulation 70:113, 1984.

12. Tennant R, Wiggers CJ: The effect of coronary occlusion on myocardial contraction. Am J Physiol 112:351, 1935.

13. Theroux P, Ross J Jr, Franklin D, Covell JW, Bloor CM, ing abnormalities in relation to the myocardium at risk. AM HEART J 111:587, 1986

20. Gillam LD, Franklin TD, Foale RA, Wiske PS, Guyer DE Hogan RD, Weyman AE: The natural history of regional wall motion in the acutely infarcted canine ventricle. J Am Coll Cardiol 7:1325, 1986. 